\title{
O DESENVOLVIMENTO DAS COMPETÊNCIAS SOCIOEMOCIONAIS NA ELABORAÇÃO DO DOCUMENTO CURRICULAR DE ENSINO RELIGIOSO DO ESTADO DO ESPÍRITO SANTO ${ }^{1}$
}

\author{
The development of socioemotional skills in the preparation of the curricular \\ document for religious education of the Espirito Santo state
}

\author{
Valéria Gon Zortéa ${ }^{2}$ \\ Érica Rezende Perini ${ }^{3}$ \\ Helenice Maria Barcellos Bergmann ${ }^{4}$
}

\section{Resumo:}

O presente artigo tem por finalidade explanar como as competências socioemocionais foram contempladas no Currículo do estado do Espírito Santo, na área de conhecimento Ensino Religioso. Buscamos narrar acerca da importância de tais competências para a vida escolar dos e das estudantes. Para tanto, consideramos os temas integradores apontados no Documento Curricular, bem como a relevância de considerar a formação integral dos alunos, sobretudo a partir da religiosidade e do respeito às diferenças. Prospectamos essa questão com intento de aventar possibilidades para que haja a integração do Ensino Religioso com outras aprendizagens no contexto escolar. Foi possível compreender que o Ensino Religioso, quando trabalhado como preconizam os marcos legais da educação - de forma não confessional, e atrelado às competências socioemocionais, pode contribuir com a formação do caráter dos alunos, considerando-os como sujeitos de aprendizagem, possuidores de direitos e de deveres, uma vez que trata, diretamente, de valores religiosos e humanos. Palavras-chave: Ensino Religioso; Competências Socioemocionais; Currículo; Formação Integral.

\section{Abstract:}

The purpose of this article is to explain how socioemotional skills were contemplated in the Espírito Santo State Curriculum, in the area of Religious Education knowledge. We seek to narrate about the importance of such skills for students' school life. To this end, we consider the integrating themes pointed out in the Curricular Document, as well as the relevance of considering the integral education of students, especially from religiosity and respect for

1 Submetido em: 05.08.2020. Aceito em: 30.09.2020.

2 Graduação em Pedagogia pela Faculdade de Filosofia, Ciências e Letras de Colatina, FAFIC, ES. Especialização em Planejamento Educacional, Supervisão Escolar e Informática Educativa. Mestranda em Ciências das Religiões na Faculdade Unida de Vitória, ES. Contato: valeriazortea@gmail.com

3 Graduação em Química pela Universidade Federal de Juiz de Fora, MG. Especialização em Química, Gestão Industrial e Novas Tecnologias Educacionais. Mestrado em Ciência, Tecnologia e Educação pela Faculdade Vale do Cricaré, ES. Contato: ericaperini@gmail.com

4 Graduação em Geografia pela Universidade Federal de Minas Gerais, MG. Especialização em Informática Educativa e Planejamento Educacional. Mestrado em Educação pela Universidade Federal do Espírito Santo, ES. Doutorado em Educação pela Universidade de São Paulo, SP. Contato: helenice.vitoria@gmail.com

Protestantismo em Revista | São Leopoldo | v. 46, n. 01 | p. 20-36| Jan./jun. 2020

Disponível em: <http://periodicos.est.edu.br/index.php/nepp> 
differences. We prospect this issue, with the intention of advancing possibilities for the integration of Religious Education with other learning in the school context. It was possible to understand that Religious Education, when worked as recommended by the legal frameworks of education - in a non-confessional way, and linked to socio-emotional competences, can contribute to the formation of the students' character, considering them as subjects of learning, having rights and duties, since it deals directly with religious and human values.

Keywords: Religious Education; Socio-emotional competences; Curriculum; Integral raining.

\section{Introdução}

A escola, enquanto instituição social, se depara com grandes desafios no tocante à sua identidade e, mediante isso, a educação contemporânea precisa ser um processo dinâmico, que necessita ser renovado e trabalhado com criatividade o tempo todo, na qual se faz necessário, inclusive, romper com o distanciamento entre os sujeitos por meio da mudança de comportamentos, de valores e de sentimentos um para com o outro. Nesse contexto, a motivação deste ensaio é mostrar como as competências socioemocionais nos e nas estudantes, abordadas por meio dos temas integradores e das competências apresentadas no Documento Curricular do Ensino Religioso do Espírito Santo, podem contribuir para a formação de estudantes capazes de lidar com as diferenças de maneira respeitosa, uma vez que atitudes como a agressividade, a coação, o dano e o assédio moral tornam-se cada vez mais presentes no dia a dia.

Segundo Ferreira e Brandenburg, "nos últimos anos a palavra intolerância tornou-se a tônica dos noticiários e o motivo de muitos atos desumanos, de violência extrema" ${ }^{5}$, e, mediante isso, os autores acreditam que "o Ensino Religioso, enquanto área do conhecimento pode ser contextualizado e, de certa forma, pode estabelecer diretrizes que contribuam para uma educação mais humanizada, plural e pacifista. No entanto, o desafio para que tudo aconteça é grande" ${ }^{\prime 6}$.

O Ensino Religioso, abordado dentro de uma perspectiva não confessional e pública, só se materializou legalmente enquanto disciplina do sistema educacional brasileiro a partir do disposto no Artigo 33 da Lei de Diretrizes e Bases da Educação (LDB) ${ }^{7}$, uma vez que este componente curricular "é parte integrante da formação básica do cidadão e constitui disciplina dos horários normais das escolas públicas de ensino fundamental, assegurado o respeito à diversidade cultural religiosa do Brasil, vedadas quaisquer formas de proselitismo" 8 . Somente após a homologação da LDB, os conteúdos de cunho religioso abordados na educação básica passaram a ser expostos sob viés laico e pluralista. $E$, no que se refere às competências socioemocionais, a LDB discorre, ao longo de seu texto, a necessidade de se

5 FERREIRA, Renan da Costa; BRANDENBURG, Laude Erandi. O Ensino Religioso e a BNCC: Possibilidades de se educar para a paz. Caminhos, Goiânia, v. 17, n. 2, p. 508-522, 2019. Disponível em: <http://seer.pucgoias.edu.br/index.php/caminhos/article/view/7313>. Acesso em: 20 jul. 2020, p. 515.

6 FERREIRA; BRANDEMBURG, 2019, p. 518.

7 BRASIL. Lei de Diretrizes e Bases da Educação - Lei no. 9.394 de 20 de dezembro de 1996: estabelece as Diretrizes e Bases da Educação Nacional. Disponível em: <http://www.planalto.gov.br/ccivil_03/leis/l9394. htm>. Acesso em: 20 abr. 2020.

8 BRASIL, LDB, 1996.

Protestantismo em Revista | São Leopoldo | v. 46, n. 01 | p. 20-36| Jan./jun. 2020

Disponível em: <http://periodicos.est.edu.br/index.php/nepp> 
estabelecer aprendizagens basilares, além da aplicação dos conteúdos básicos e mínimos para a formação discente.

De acordo com a LDB, o componente curricular Ensino Religioso, de oferta obrigatória e matrícula facultativa, é ministrado apenas para o Ensino Fundamental e faz parte da área de conhecimento das Ciências Humanas e Sociais Aplicadas, tendo em vista seu aspecto histórico e, também, por sua base filosófica, o que o aproxima a essa área. Além disso, o Ensino Religioso pode ser de grande valia para o conhecimento da diversidade de cultura e de religião sob a perspectiva dos direitos humanos.

No entanto, as inúmeras propostas pedagógicas disponíveis pelo país mostraram pontos bastante divergentes, que ressaltaram ainda mais as desigualdades existentes na educação básica. Surge, então, no ano de 2015, o início da construção da Base Nacional Comum Curricular $(\mathrm{BNCC})^{9}$, com o intento de unificar as influências e às referências das instituições de ensino e de solucionar a ausência de conexão presente nos documentos escolares, com olhar e foco direcionados para o aprendizado. O Documento foi elaborado a partir de um processo democrático e colaborativo, sob liderança do Ministério da Educação (MEC).

O Ensino Religioso deixou de ser apenas um componente curricular, não pertencendo mais à área de Ciências Humanas conforme antes definido na LDB, e tornou-se uma área do conhecimento específica. Assim, de acordo com a BNCC, o Ensino Fundamental passou a contar com cinco áreas distintas: Linguagens, Matemática, Ciências da Natureza, Ciências Humanas e Ensino Religioso. Isso levou a alteração dos marcos legais que normatizam e objetivam a educação básica do Brasil.

Diferentemente da LDB, que trata das competências socioemocionais de forma não específica ao longo de seu texto, a BNCC preconiza que, ao longo da educação básica os estudantes desenvolvam não somente às competências cognitivas em sua formação, mas também as socioemocionais. Para tanto, faz-se necessário investir na educação integral dos e das estudantes, contemplando a totalidade do ser em seus diferentes aspectos (estéticos, éticos, cognitivo, afetivo, cultural, biológico, social e, também, religioso), estabelecendo-se, assim, os princípios norteadores para o currículo, a saber: o conhecimento escolar; a valorização da vida em todas as suas dimensões e, ainda, o reconhecimento da diversidade na formação humana.

A atual compreensão do Ensino Religioso enquanto área do conhecimento humano implica no entendimento que tem por base a diversidade presente nas diferentes expressões religiosas. Com isso, este componente curricular pode contribuir para o (re) conhecimento e o respeito às diferentes expressões religiosas oriundas da elaboração cultural, que compõem a sociedade brasileira, além de permitir o acesso às diversas fontes da cultura sobre o fenômeno religioso, tendo como foco o sagrado. Assim,

Introduzir o Ensino Religioso na sala de aula implica refletir e integrar o fenômeno religioso como saber fundamental para a formação integral do aluno. Para que isso

\footnotetext{
${ }^{9}$ BNCC: documento de caráter normativo que define o conjunto orgânico e progressivo de aprendizagens essenciais que todos os alunos devem desenvolver ao longo das etapas e modalidades da Educação Básica, de modo a que tenham assegurados seus direitos de aprendizagem e desenvolvimento, em conformidade com o que preceitua o Plano Nacional de Educação (PNE).
}

Protestantismo em Revista | São Leopoldo | v. 46, n. 01 | p. 20-36| Jan./jun. 2020 
aconteça é necessário superar um desafio principal: superar o preconceito religioso respeitando a diversidade cultural e religiosa. ${ }^{10}$

A partir do desenvolvimento das competências socioemocionais, o aluno será capaz de se relacionar consigo mesmo e com os outros, de compreender e gerir às emoções, de enfrentar situações adversas, além de tomar decisões responsáveis, solidárias e autônomas. Mediante todo cenário exposto, é importante ressaltar, contudo, que a BNCC não se traduz em um currículo, mas sim em um documento norteador para que as redes de ensino elaborem seus documentos curriculares, considerando as especificidades e às particularidades metodológicas, sociais e regionais. Desse modo, este artigo almeja abordar como a temática das competências socioemocionais estão contempladas no Documento Curricular de Ensino Religioso do Espírito Santo, que foi elaborado de maneira alinhada à BNCC, uma vez que entendemos a relevância das referidas competências no processo de ensino-aprendizagem.

O intento do presente artigo não é apresentar resultados de uma possível medição, mas apenas expor uma revisão bibliográfica de forma a apresentar os caminhos delineados pela Secretaria de Estado da Educação do Espírito Santo (Sedu), para contemplar às competências socioemocionais na elaboração do Documento Curricular de Ensino Religioso da rede pública estadual de ensino. Desse modo, não explanamos acerca de um método de pesquisa, mas sobre como a Sedu trabalhou o componente curricular Ensino Religioso sob um viés não confessional, conforme Artigo 33 da LDB, e contemplando, sobretudo, a formação integral do estudante, assim como sugerido na BNCC, documento norteador para a elaboração dos currículos.

\section{Relação entre às Competências Socioemocionais e o Ensino Religioso}

Quando às propostas pedagógicas de ensino incluem que o desenvolvimento das competências socioemocionais é relevante para a aprendizagem integral dos estudantes, diversas transformações no cotidiano escolar acontecem, que se manifestam em variadas oportunidades de aprendizagem e, também, nas relações estabelecidas entre professores e alunos ou entre alunos e alunos, uma vez que eles passam a se descobrir enquanto aprendem. Os estudantes se tornam capazes de reconhecer o que gostam de estudar, suas principais dificuldades, quais hábitos permitem melhor gestão do tempo para o desempenho das tarefas e, também, a melhor maneira para aprender. Também fica evidente quais emoções os dominam perante uma situação de fracasso ou quando são provocados.

Às competências socioemocionais estão estreitamente relacionadas com as competências cognitivas. Nesse sentido, os currículos precisam estabelecer suas matrizes de competências de forma que o ensino dos componentes curriculares seja ressignificado e complementado por elementos inovadores capazes de estabelecer essa relação entre o cognitivo e o socioemocional. Afinal, em tempos marcados por sucessivas ondas de violência, conflitos e disputas, o debate se torna essencial, visando uma reflexão aprofundada do papel de cada sujeito no mundo, haja vista a pluralidade e a singularidade desses sujeitos. Assim,

10 SILVA, Isaac Pinto da. Ensino religioso em sala de aula: contribuições à formação do aluno e à aprendizagem de valores. Unitas, Vitória, v. 2, p. 166-174, 2014. Disponível em: <http://revista.faculdadeunida.com.br/index.php/unitas>. Acesso em: 20 abr. 2020, p. 168.

Protestantismo em Revista | São Leopoldo | v. 46, n. 01 | p. 20-36| Jan./jun. 2020

Disponível em: <http://periodicos.est.edu.br/index.php/nepp> 
essas questões podem ser melhor efetivadas na medida em que o Ensino Religioso e a escola também contribuírem para fortalecer, cotidianamente, o respeito à diversidade, pois,

\begin{abstract}
O mais simples e eficaz alicerce para a construção da paz na sociedade humana é a humildade para reconhecer que a verdade não é monopólio da própria fé, religião ou política. E, no Ensino Religioso, através do espírito de reverência às crenças alheias, não apenas a tolerância, desencadeia-se o profundo respeito mútuo que pode conduzir à paz. ${ }^{11}$
\end{abstract}

Nesse contexto, as competências socioemocionais desempenham um papel fundamental para que o sucesso escolar das crianças e jovens seja alcançado. Segundo o mesmo autor, "A Escola possui a função de auxiliar o educando a se libertar de estruturas opressoras que o impedem de avançar e progredir"12. Para que se alcance tal realidade, é preciso estabelecer uma matriz de competências concretamente relacionada com os resultados pretendidos da aprendizagem, tanto cognitiva quanto socioemocional, uma vez que o resultado será o desenvolvimento integral do indivíduo atrelado a uma boa convivência em sociedade.

O construto competência socioemocional tem sido destacado na literatura pela sua relação com a qualidade do desenvolvimento e ajustamento social e emocional de crianças e adolescentes, contribuindo tanto para a promoção quanto para a avaliação do nível de prazer e bem-estar ao longo da vida. ${ }^{13}$

As competências socioemocionais compreendem, assim, uma série de competências que os sujeitos possuem para se relacionar uns com os outros, para lidar com suas próprias emoções e para estabelecer metas de vida. Desse modo, torna-se possível construir relações mais saudáveis para viver em sociedade. Nesse sentido, Ferreira e Brandenburg propõem uma reflexão sobre como o Ensino Religioso enquanto área do conhecimento pode colaborar para uma educação que perpetue, de maneira ou de outra, a cultura da paz, uma vez que o Brasil é um dos países onde mais se registram múltiplas formas de violência e "é contraditório que um país reconhecido por sua diversidade sofra, muitas vezes, pela falta de compreensão e respeito" ${ }^{14}$.

Historicamente, o objetivo principal do processo de ensino-aprendizagem sempre foi o desenvolvimento cognitivo do estudante. Contudo, o cenário educacional encontra-se em transformação, sendo perceptível que as competências socioemocionais são primordiais em todos os aspectos da vida humana, até mesmo para o desenvolvimento de competências cognitivas, com viés acadêmico e científico.

Às competências socioemocionais são intrínsecas do ser humano e fazem parte de diversas circunstâncias do cotidiano, integrando os processos relacionados com o "aprender",

11 ROCHA, Marcos Porto Freitas da. O Ensino Religioso na escola pública brasileira - Relação entre o conhecimento religioso e a escola. Revista Valore, Volta Redonda, v. 1, p. 82-94, 2016. Disponível em: $<$ https:// revistavalore.emnuvens.com.br/valore/article/view/19>. Acesso em: 21 jul. 2020, p. 89.

12 ROCHA, 2016, p. 91.

13 MARIN, Angela Helena; et al. Competência socioemocional: conceitos e instrumentos associados. Revista Brasileira de Terapias Cognitivas, v. 13, p. 92-103, 2017. Disponível em: <http://dx.doi.org/10.5935/18085687.20170014>. Acesso em: 19 jul. 2020, p. 92.

${ }^{14}$ FERREIRA; BRANDEMBURG, 2019, p. 511.

Protestantismo em Revista | São Leopoldo | v. 46, n. 01 | p. 20-36| Jan./jun. 2020

Disponível em: <http://periodicos.est.edu.br/index.php/nepp> 
o "conhecer", o "ser", o "conviver" e o "trabalhar", entretanto, é essencial que elas sejam estimuladas e trabalhadas ao longo de toda a vida. As competências socioemocionais reverberam no processo de ensino-aprendizagem. Assim, "acredita-se que o foco deva ser estimular o aprendizado de tais competências, independente de os alunos já as terem desenvolvido ou não."15 A educação carece incorporar, a partir de seus conteúdos curriculares, uma formação consolidada para a vida em sociedade, uma vez que, ela proporciona diferentes possibilidades de mudança e, por isso, para Ferreira e Brandenburg:

O Ensino Religioso como componente curricular na educação brasileira, também está comprometido com esse desafio, visto que seus objetivos, habilidades e competências preconizados na BNCC prezam pela valorização da vida, pelo respeito aos Direitos Humanos, pelo reconhecimento das diferentes formas de expressão cultural, pela propositura de uma cultura do diálogo e de paz. ${ }^{16}$

Existem diversas maneiras de possibilitar o desenvolvimento das competências socioemocionais, que geralmente envolvem o conhecimento sobre si mesmo, a percepção do outro e das relações sociais, além da identificação das emoções e do bom senso. Uma sociedade formada por sujeitos capazes de expor suas opiniões a respeito de temas polêmicos, como no caso da diversidade religiosa, de forma pautada no respeito a opinião do outro, se concretizará na construção de valores pertinentes ao homem. Mediante isso, segundo Ferreira e Brandenburg, o Ensino Religioso precisa inserir elementos que pontuem uma cultura de paz, uma vez que:

Cada vez mais cresce o número de casos de intolerância religiosa no Brasil. O país da diversidade passa a usar da própria diversidade como ponto de confronto, de violência, de intolerância. Os discursos de ódio têm se espalhado até mesmo em pregações religiosas que, ao invés de promoverem a dignidade e a valorização da vida, buscam elementos confessionais e dogmáticos como forma de exaurir aquilo que se torna diferente. ${ }^{17}$

Nesse contexto, entendemos que as competências socioemocionais podem ser aliadas neste desafio, uma vez que, por meio delas é possível formar sujeitos críticos e capazes tomar decisões que visem o bem comum, além de promoverem o convívio harmonioso entre as pessoas. Desse modo, torna-se relevante pautar as aulas de Ensino Religioso no desenvolvimento da formação integral do estudante, de modo a fortalecer e ampliar espaços seguros de diálogos necessários a superação de preconceitos, de discriminações e de intolerâncias no ambiente escolar.

\section{O Currículo de Ensino Religioso no Estado do Espírito Santo}

A implementação do Currículo no Estado do Espírito Santo na rede pública estadual de ensino aconteceu no ano de 2019. A elaboração deste Documento Curricular se deu de forma alinhada à BNCC, documento norteador que define as aprendizagens essenciais para os estudantes da educação básica no país, e considerou às especificidades locais do estado, além de proporcionar o desenvolvimento de competências e habilidades capazes de promover o

15 MARIN, et.al, 2017, p. 96.

${ }^{16}$ FERREIRA; BRANDENBURG, 2019, p. 511.

17 FERREIRA; BRANDENBURG, 2019, p. 511.

Protestantismo em Revista | São Leopoldo | v. 46, n. 01 | p. 20-36| Jan./jun. 2020

Disponível em: <http://periodicos.est.edu.br/index.php/nepp> 
caráter ético, autônomo, crítico-reflexivo e emancipado dos estudantes no mundo do trabalho e na vida em sociedade. Para o desenvolvimento desta ação, instituiu-se uma estrutura de governança, por meio da Portaria no 037-R/2018, visando definir a equipe de elaboração curricular. O Currículo foi produzido por pessoas educadoras educadores das redes estadual e municipais de ensino, de forma democrática e colaborativa e, ao longo do processo de elaboração, a equipe de currículo efetuou estudos aprofundados não somente da BNCC, mas também de diversos documentos normativos e marcos legais da educação nacional, de outros documentos curriculares nacionais e internacionais, e, sobretudo, de currículos já elaborados pela rede pública estadual de educação do Espírito Santo, no caso o Currículo Básico Escola Estadual (CBEE).

Assim, sua construção proporcionou um novo olhar sobre o currículo, uma vez, com o intento de construir um Currículo contemporâneo, capaz de propiciar uma educação mais justa, democrática, inclusiva e com equidade, a sociedade atuou dialogicamente, partilhando seus interesses, necessidades cruciais e seus anseios. $E$, de forma complementar, visando considerar as especificidades locais/regionais, as redes envolvidas inseriram outros componentes que específicos para a sua realidade.

Como consequência, o Documento Curricular do Espírito Santo se orienta a partir de princípios pautados na Educação Integral, entendida como aquela que proporciona o desenvolvimento do sujeito não apenas na dimensão intelectual, mas também contempla às dimensões social, emocional, física, cultural e política, ou seja, compreendendo-o em sua integralidade. Assim, a educação integral, comprometida com o desenvolvimento de competências, presume uma matriz de saberes pautada nos quatro pilares da educação ${ }^{18}$, da Unesco: aprender a ser; aprender a conhecer; aprender a fazer e aprender a conviver.

Nesse contexto, se fez necessário uma reestruturação do currículo, capaz de abarcar tempos e espaços que proporcionem conhecimentos disciplinares sob a perspectiva da aprendizagem integral dos alunos, articulando conhecimentos, habilidades e atitudes que possibilitem o seu desenvolvimento. Desse modo, as cinco áreas de conhecimento do Ensino Fundamental, apresentadas do Currículo do Espírito Santo, devem se comprometer com a matriz de saberes definida para toda a Educação Básica, cuja proposta é colaborar para a formação de uma sociedade mais democrática, inclusiva e sustentável.

No entanto, neste Documento Curricular não somente buscou-se desenvolver as habilidades previstas nos conteúdos, como aprendizado, criatividade, memória e pensamento crítico, bem como contemplou-se a necessidade de trabalhar as competências socioemocionais com os discentes, evidenciando-se a importância do desenvolvimento de capacidades para lidar com as emoções. Considerou-se, sobretudo, as peculiaridades de cada região do estado. Assim, além dos doze temas integradores que já compunham a $\mathrm{BNCC}^{19}$, no

18 Os quatro pilares da educação são conceitos de fundamento da educação e definem os aprendizados considerados essenciais para que as crianças se desenvolvam cognitivamente e socialmente. Os Pilares foram publicados em 1999 pela Comissão Internacional sobre Educação para o Século XXI, coordenada por Jacques Delors, no relatório "Educação: um tesouro a descobrir", da Unesco.

19 Temas Integradores propostos na BNCC: Direito da criança e do Adolescente; Educação para o Trânsito; Educação Ambiental; Educação Alimentar e Nutricional; Processo de Envelhecimento, Respeito e Valorização do Idoso; Educação em Direitos Humanos; Educação das Relações Étnico-Raciais e Ensino de História e Cultura Afro-Brasileira, Africana e Indígena; Saúde; Vida Familiar e Social; Educação para o Consumo; Educação Financeira e Fiscal; Trabalho, Ciência e Tecnologia; Diversidade Cultural.

Protestantismo em Revista | São Leopoldo | v. 46, n. 01 | p. 20-36| Jan./jun. 2020

Disponível em: <http://periodicos.est.edu.br/index.php/nepp> 
decorrer da elaboração do Documento Estadual, sentiu-se a necessidade de acrescentar novos temas e de retomar alguns já propostos, direcionando o olhar para as especificidades do estado, a saber:

- Educação para o Consumo Consciente (alterado);

- Diversidade Cultural, Religiosa e Étnica (alterado);

- Trabalho e Relações de Poder, Ética e Cidadania (novo);

- Gênero, Sexualidade, Poder e Sociedade (novo);

- Povos e Comunidades Tradicionais (novo);

- Educação Patrimonial (novo);

- Diálogo Intercultural e Inter-religioso (novo).

Os Temas Integradores provocam o exercício do diálogo construtivo e concebem novas relações, capazes de interferir nos processos de construção de identidade e no modo de interação entre os sujeitos, sendo possível, assim, construir uma sociedade mais igualitária, solidária, participativa, responsável e inclusiva.

Os temas integradores entrelaçam as diversas áreas de conhecimento que compõem o Currículo do Espírito Santo e trazem questões que atravessam as experiências dos sujeitos em seus contextos de vida, ações no público, no privado e no cotidiano. Compreende aspectos para além da dimensão cognitiva, dando conta da formação social, política e ética e que considera e valoriza as diversas identidades culturais. ${ }^{20}$

No que tange, especificamente, a abordagem do Ensino Religioso, o Currículo do Espírito Santo traz a temática Diversidade Cultural, Religiosa e Étnica (alteração da proposta Diversidade Cultural, da BNCC), que foi pensada com o intento de promover a tolerância e o respeito às diversidades existentes no estado, cuja mistura religiosa étnica e cultural é grande. Ademais, tem-se, ainda, o novo tema integrador Diálogo Intercultural e Inter-Religioso, tendo em vista os tempos vivenciados, na qual uma multiplicidade de ideais religiosos e multiculturais estão presentes por todos os lados. De acordo com Martins e Rodrigues:

No Ensino Religioso, o que se pretende não é dizer se essa ou aquela religião são mais verdadeiras do que outras [...]. Antes, o que se pretende é construir um conhecimento sobre as tradições religiosas constitutivas do campo religioso conhecido pela comunidade escolar, com o intuito de dar ocasião para que esse conhecimento resulte em respeito pelas alteridades, diferentes pontos de vista e distintas formas de ser-no-mundo. ${ }^{21}$

20 ESPÍRITO SANTO. Currículo do Espírito Santo. Área de Conhecimento: Ensino Religioso. Componente curricular - Ensino Religioso. Governo do Estado do Espírito Santo, Secretaria da Educação, Vitória, 2018. Disponível em: < https://sedu.es.gov.br/Media/sedu/pdf\%20e\%20Arquivos/Curriculo_ES_Ensino_Religioso. pdf>. Acesso em: 20 jul. 2020. p. 19.

21 MARTINS, Nathália Ferreira de Sousa; RODRIGUES, Elisa. Aspectos teóricos e didáticos da formação do professor de ensino religioso: perspectivas à luz da Ciência(s) da(s) Religião(ões) e da Base Nacional Comum Curricular. Caminhando, São Bernardo do Campo, v. 23, n. 2, p. 137-150, 2018. Disponível em: <https://www.metodista.br/revistas/revistas-ims/index.php/Caminhando/article/view/9049/0>. Acesso em: 17 jul. 2020, p. 149.

Protestantismo em Revista | São Leopoldo | v. 46, n. 01 | p. 20-36| Jan./jun. 2020

Disponível em: <http://periodicos.est.edu.br/index.php/nepp> 
A religião se constituiu a partir da crença pelo divino e o ser humano busca nela um conforto para seus problemas, sejam eles de cunho pessoal ou espiritual. Diante disso, falar sobre religião se torna um desafio, uma vez que alcança o íntimo das pessoas. Além disso, é preciso considerar e aceitar toda a diversidade religiosa existente, de forma a estabelecer um diálogo construtivo com ela, almejando enfraquecer os preconceitos e as intolerâncias. Tal fato pode ser alcançado por meio dos temas integradores "Diversidade Cultural, Religiosa e Étnica" e "Diálogo Intercultural e Inter-Religioso", trabalhados com base no respeito, no crescimento mútuo e nas relações de igualdade entre diferentes culturas, etnias e religiões.

Cabe ao Ensino Religioso tratar os conhecimentos religiosos a partir de pressupostos éticos e científicos, sem privilégio de nenhuma crença ou convicção. Isso implica abordar esses conhecimentos com base nas diversas culturas e tradições religiosas, sem desconsiderar a existência de filosofias seculares de vida. ${ }^{22}$

Dessa forma, os objetivos de aprendizagem e às habilidades trabalhadas no Ensino Religioso precisam sugerir o respeito às diferentes identidades, a valorização da pluralidade religiosa e às manifestações culturais, garantindo, assim, uma educação pautada em valores.

No Ensino Fundamental, o Ensino Religioso adota a pesquisa e o diálogo como princípios mediadores e articuladores dos processos de observação, identificação, análise, apropriação e ressignificação de saberes, visando o desenvolvimento de competências específicas. Dessa maneira, busca problematizar representações sociais preconceituosas sobre o outro, com o intuito de combater a intolerância, a discriminação e a exclusão. ${ }^{23}$

Entende-se, assim, que quando o Ensino Religioso é ministrado dentro de uma abordagem que almeja mudar comportamentos que comprometem a convivência democrática, a criança/adolescente, cursando o ensino fundamental, desenvolverá competências que lhes darão condições de compreender o fenômeno religioso, o respeito pela diversidade religiosa, o direito à liberdade religiosa, além da influência da religião nas diversas comunidades. Ao mesmo tempo, fica estabelecimento o compromisso com a melhoria do mundo em que se vive.

Em suma, o texto de caracterização do Ensino Religioso apresentado no Documento Curricular, elaborado para o estado do Espírito Santo, pontua que o conhecimento religioso, objeto de estudo da área de Ensino Religioso, se fundamenta nas diferentes áreas do conhecimento das Ciências Humanas e Sociais, em especial da Ciência da(s) Religião(ões). Além disso, enquanto área de conhecimento, o Ensino Religioso pode viabilizar a compreensão, a interpretação e a ressignificação da religiosidade e, também, do fenômeno religioso, de forma não confessional, considerando às diversas manifestações históricas, às linguagens e às paisagens religiosas existentes nas culturas e nas sociedades.

\section{Considerações Finais}

O presente artigo foi esboçado com o propósito de explanar sobre como às competências socioemocionais, tão relevantes para a vida escolar dos estudantes do ensino

22 ESPÍRITO SANTO, 2018, p. 49.

23 ESPÍRITO SANTO, 2018, p. 49.

Protestantismo em Revista | São Leopoldo | v. 46, n. 01 | p. 20-36| Jan./jun. 2020

Disponível em: <http://periodicos.est.edu.br/index.php/nepp> 
fundamental no mundo contemporâneo, foram contempladas no Currículo de Ensino Religioso do Espírito Santo, por meio de uma revisão bibliográfica. A educação apresenta desafios que perpassam pela transmissão do conhecimento, da informação e da comunicação, uma vez que o mundo contemporâneo envolve o desenvolvimento de competências além das cognitivas. Compete, então, a escola de tempo parcial ou integral, e ao processo educacional como um todo, comprometer-se com o desenvolvimento do sujeito em suas diferentes dimensões.

O Currículo de Ensino Religioso elaborado para o estado do Espírito Santo apresenta como os objetivos de aprendizagem estabelecidos na BNCC serão alcançados, uma vez que a Base, que estabelece tais objetivos, foi o principal documento norteador. Mediante isso, o Documento considera as singularidades, os novos problemas e às questões a serem incorporadas, de acordo com às peculiaridades de cada região do estado e, por este motivo, fez-se necessário acrescentar novos temas integradores e reelaborar outros que foram propostos pela BNCC, voltando o olhar para as particularidades do estado.

A partir deste estudo, foi possível inferir vários aspectos relativos à temática escolhida e, perante o exposto, compreendemos que, quando trabalhado numa perspectiva não confessional, atrelado às competências socioemocionais, o Ensino Religioso pode colaborar com a formação do caráter dos estudantes do ensino fundamental, considerandoos como sujeitos de aprendizagem, possuidores de direitos e de deveres, uma vez que trata, diretamente, de valores religiosos e humanos, considerando às diversidades. Ademais, o convívio respeitoso entre sujeitos de diferente credos religiosos e culturas será promovido.

Em suma, o componente curricular Ensino Religioso reforçará ideias e conceitos que são julgados relevantes para a sociedade contemporânea, promovendo uma visão harmônica de mundo para os alunos, a partir da promoção do conhecimento e da autonomia, levandoos a se realizarem em todas as suas dimensões. Assim, o Ensino Religioso, enquanto área de conhecimento e componente curricular, busca fomentar a compreensão e o respeito às diferentes religiões, culturas e etnias existentes, sob a perspectiva de atividades que promovem o diálogo de modo singular, criando novas formas de compreender o mundo.

\section{Referências}

BRASIL. Lei de Diretrizes e Bases da Educação - Lei no. 9.394 de 20 de dezembro de 1996: estabelece as Diretrizes e Bases da Educação Nacional. Disponível em: <http://www. planalto. gov.br/ccivil_03/leis/19394.htm>. Acesso em: 20 abr. 2020.

ESPÍRITO SANTO. Currículo do Espírito Santo. Área de Conhecimento: Ensino Religioso. Componente curricular - Ensino Religioso. Governo do Estado do Espírito Santo, Secretaria da Educação, Vitória, 2018. Disponível em: < https://sedu.es.gov.br/Media/sedu/pdf\%20e\% 20Arquivos/Curriculo_ES_Ensino_Religioso.pdf>. Acesso em: 20 jul. 2020.

FERREIRA, Renan da Costa; BRANDENBURG, Laude Erandi. O Ensino Religioso e a BNCC: Possibilidades de se educar para a paz. Caminhos, Goiânia, v. 17, n. 2, p. 508-522, 2019. Disponível em: <http://seer.pucgoias.edu.br/index.php/caminhos/article/view/7313>. Acesso em: 20 jul. 2020.

Protestantismo em Revista | São Leopoldo | v. 46, n. 01 | p. 20-36| Jan./jun. 2020

Disponível em: <http://periodicos.est.edu.br/index.php/nepp> 
MARIN, Angela Helena; et al. Competência socioemocional: conceitos e instrumentos associados. Revista Brasileira de Terapias Cognitivas, v. 13, p. 92-103, 2017. Disponível em: <http://dx.doi.org/10.5935/1808-5687.20170014>. Acesso em: 19 jul. 2020.

MARTINS, Nathália Ferreira de Sousa; RODRIGUES, Elisa. Aspectos teóricos e didáticos da formação do professor de ensino religioso: perspectivas à luz da Ciência(s) da(s) Religião(ões) e da Base Nacional Comum Curricular. Caminhando, São Bernardo do Campo, v. 23, n. 2, p. 137-150, 2018. Disponível em: <https://www.metodista.br/revistas/revistasims/index.php/Caminhando/article/view/9049/0>. Acesso em: 17 jul. 2020.

ROCHA, Marcos Porto Freitas da. O Ensino Religioso na escola pública brasileira - Relação entre o conhecimento religioso e a escola. Revista Valore, Volta Redonda, v. 1, p. 82-94, 2016. Disponível em: <https://revistavalore.emnuvens.com.br/valore/article/view/19>. Acesso em: 21 jul. 2020.

SILVA, Isaac Pinto da. Ensino religioso em sala de aula: contribuições à formação do aluno e à aprendizagem de valores. Unitas, Vitória, v. 2, p. 166-174, 2014. Disponível em: <http://revista.faculdadeunida.com.br/index.php/unitas>. Acesso em: 20 abr. 2020. 